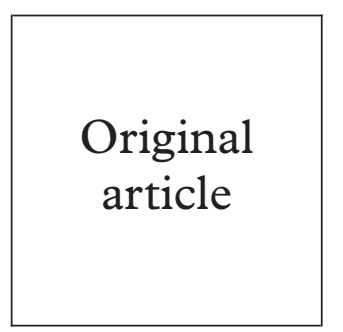

\title{
Management of women with recurrent genital herpes in pregnancy in Australia
}

\author{
C Marks, K Fethers, A Mindel
}

Objective: To document clinical practice for the management of recurrent genital herpes in pregnant women in Australia.

Design and participants: A questionnaire to all doctors associated with the Royal Australian College of Obstetricians and Gynaecologists.

Main outcome measures: Policies for antenatal herpes screening, circumstances in which delivery by caesarean section was considered appropriate, and the use of aciclovir during pregnancy. The results were analysed by college status, sex, and whether the doctor worked in a public or private facility.

Results: 2855 (67.3\%) obstetricians returned questionnaires. 696 (34.3\%) stated that their hospital had a policy for managing recurrent genital herpes in pregnancy: $44.5 \%$ examined the genitalia and $33.8 \%$ took cultures during pregnancy. Fellows were more likely to examine the genitalia $(87 \%$ v $37 \%, \mathrm{p}<0.001)$, and more likely to perform antenatal viral cultures than members $(75 \%$ $v 30 \%, \mathrm{p}<0.001$ ). Doctors working at private hospitals were significantly more likely to take viral cultures than doctors in public hospitals $(39 \% v 33 \% \mathrm{p}<0.05)$. Doctors were asked to consider five scenarios and judge whether caesarean section would be appropriate. $96 \%$ considered that a caesarean section was appropriate in women with active herpes at the onset of labour. In the case of a recurrence of genital HSV at the time of presentation with ruptured membranes longer than 4 hours, diplomats $(79 \%)$ were significantly more likely to recommend a caesarean section than fellows $(64 \%)$, members $(63 \%)$, or trainees $(49 \%)$ (all $p \leqslant 0.001)$. Where there were positive viral cultures before the onset of labour fellows (45\%) were more likely than members $(29 \%)$ $(\mathrm{p}=0.005)$, males $(62 \%)$ were more likely than females $(55 \%)(\mathrm{p}=0.03)$, and doctors working in private hospitals $(69 \%)$ were more likely than those in the public sector $(54 \%)(\mathrm{p}<0.001)$ to recommend caesarean section.

Conclusion: There is considerable divergence of opinion regarding the appropriate management of recurrent genital herpes in pregnancy. The implementation of management guidelines would provide consistency of care.

(Sex Transm Inf 1999;75:55-57)

Keywords: genital herpes; pregnancy; Australia

\section{Introduction}

Neonatal herpes is a serious condition with 50-60\% mortality. Antiviral treatment reduces mortality but the majority of the survivors are left with profound neurological damage. ${ }^{1}$ The condition is rare in Australia, with an estimated incidence of one in 11000 live births. ${ }^{2}$ In contrast, HSV-2 infection is common in adults, occurring in $15-75 \%$ of people attending STD clinics, and $12-50 \%$ of women attending antenatal clinics. ${ }^{3}$

The major risk to the baby occurs if the mother acquires herpes simplex virus (HSV) for the first time during late pregnancy, the risk being in the order of 40-60\%. ${ }^{4}$ Recurrent genital herpes constitutes a very small risk of transmission to the baby. ${ }^{5}$ However, despite this low risk there is still considerable concern and confusion regarding appropriate management of recurrent HSV in pregnancy.

Future management recommendations in Australia require an accurate knowledge of the existing management approaches to recurrent genital herpes in pregnancy. Consequently, we conducted this study to determine the attitudes and practice of doctors managing pregnant women with a history of recurrent genital herpes based on a similar study conducted in the United Kingdom. ${ }^{6}$

\section{Method}

In 1994 a questionnaire was posted to all fellows, members, diplomats, and trainees of the Royal Australian College of Obstetricians and Gynaecologists (RACOG). Members are those who have passed the RACOG examination and completed 4 years of teaching hospital training. Fellowship requires a further 2 years as a hospital specialist. Trainees are doctors working in training posts while enrolled in the RACOG training programme, and diplomats must have worked for at least 6 months in a training post and then passed diploma examinations. All recipients were informed that the questionnaire was confidential and those who had not returned their completed questionnaire after 2 months were sent a second questionnaire. Doctors who had no contact with antenatal patients were asked to return their questionnaire with only the demographic section completed.

Questions were designed to determine policies for antenatal herpes screening and circumstances in which delivery by caesarean section to bypass an infected birth canal was considered 
Table 1 Herpes simplex virus screening policies and practices

\begin{tabular}{lll}
\hline Membership status & $\begin{array}{l}\text { Have a hospital } \\
\text { policy }\end{array}$ & $\begin{array}{l}\text { Provided } \\
\text { screening }\end{array}$ \\
\hline Fellow & $226 / 583(39 \%)$ & $171 / 591(30 \%)$ \\
Member & $35 / 79(44 \%)$ & $16 / 77(21 \%)$ \\
Trainee & $36 / 76(47 \%)$ & $14 / 75(19 \%)$ \\
Diplomat & $394 / 1126(35 \%)$ & $370 / 1115(33 \%)$ \\
Total for all respondents & $691(37 \%)^{\star}$ & $571(31 \%) \dagger$ \\
\hline
\end{tabular}

^Five respondents failed to indicate their membership status.

†Seven respondents failed to indicate their membership status.

appropriate and to establish attitudes to the use of aciclovir for the treatment of herpes infection during pregnancy.

Results were analysed to determine the proportion of doctors who performed antenatal viral screening, modified screening (examination alone), or no screening and the proportions of the study population who performed caesarean sections for each of the five given situations. Data were entered and evaluated using the Statistical Package for the Social Sciences (SPSS), ${ }^{7}$ using descriptive statistics, analysis of variance (ANOVA), $t$ tests, and $\chi^{2}$ tests.

\section{Results}

The questionnaire was sent to 4242 doctors. Following two mailings, 2855 (67\%) were returned, of which 2693 (94\%) were completed. The following analyses only include the 2184 respondents who worked with antenatal patients. Six hundred and nineteen $(29 \%)$ of the respondents were fellows, $82(4 \%) \mathrm{mem}-$ bers, 1387 (64\%) diplomats, and 77 (4\%) trainees.

Hospital policies and screening practices are shown in table 1 . Less than half $(37 \%)$ of the respondents had a hospital policy for the management of genital herpes in pregnancy and only $31 \%$ provided screening. Doctors working at private hospitals $(126 / 323(39 \%))$ were significantly more likely to take viral cultures than doctors in public hospitals (216/663 (33\%) $(\mathrm{p}<0.05))$.

In women with recurrent genital herpes, $1271(86 \%)$ would examine the vulva and cervix to identify lesions at the time of labour and $559(41 \%)$ would take viral cultures. Diplomats were significantly more likely to examine the genitalia $(775 / 877(88 \%))$ and to take viral cultures $(353 / 799(44 \%))$ than fellows (374/ $472(79 \%)$ and $154 / 450(34 \%)$, both $\mathrm{p}<0.01)$. Female doctors were more likely to examine the genitalia $(374 / 412(91 \%))$ and to take viral cultures $(176 / 371(47 \%))$ than male doctors $(839 / 1000(84 \%)$ and $351 / 935(38 \%)$, both $\mathrm{p}=0.001)$.
Doctors were asked to consider whether caesarean section was appropriate for each of five scenarios (table 2). Most (1991/2079 (96\%)) considered a caesarean section was appropriate in women with herpes at delivery. In the case of a recurrence of genital $\mathrm{HSV}$ at the time of presentation with ruptured membranes longer than 4 hours, diplomats $(79 \%)$ were significantly more likely to recommend a caesarean section than the other groups $(p<0.001)$.

In the hypothetical situation of previous positive viral culture, fellows were more likely than any of the other groups to recommend caesarean section $(\mathrm{p}=0.005)$. In addition, male doctors $(555 / 899(62 \%))$ were more likely than female doctors to recommend caesarean section $(203 / 368(55 \%) ; p=0.03)$ as were doctors working in private hospitals $(225 / 324(69 \%))$ compared with those in the public system (330/610 (54\%); $\mathrm{p}<0.001)$.

Given the scenario of a woman reporting a recurrence without visible lesions, female doctors $(286 / 546(52 \%))$ were more likely than male doctors $(589 / 1334(44 \%)) \mathrm{p}=0.001)$ to recommend a caesarean section.

If a woman requested a caesarean section, fellows would agree to perform caesarean section more often than doctors in the other groups $(\mathrm{p}<0.001)$. Female doctors $(226 / 552$ $(41 \%))$ were significantly less likely to agree to perform a caesarean section at the patient's request than male doctors (630/1325 (48\%) $\mathrm{p}=0.009)$, while private doctors $(256 / 467$ $(55 \%)$ ) were significantly more likely than public doctors $(425 / 970(44 \%))$ to consent to caesarean section for this indication $(\mathrm{p}<0.001)$.

Five hundred and ninety nine $(29 \%)$ doctors had considered using aciclovir to treat recurrences during pregnancy and $873(41 \%)$ had considered suppressive aciclovir to prevent recurrences at term. There were no significant differences across membership with regard to using suppressive aciclovir in late pregnancy.

\section{Discussion}

This study has shown that there is substantial variation in the management of recurrent genital herpes in pregnancy by Australian doctors. For example, some women would have had frequent clinical examinations and viral cultures, while others would have none, and some women would have been recommended for caesarean section irrespective of clinical circumstances, while others with obvious genital herpes during labour would have been allowed a normal vaginal delivery. Private hospital doctors were more likely to screen with viral culture and had a lower threshold for intervening with

Table 2 Consideration of the need for caesarean section in five clinical scenarios

\begin{tabular}{|c|c|c|c|c|c|}
\hline Clinical scenario & Fellows & Members & Trainees & Diplomats & $p$ Value \\
\hline Active herpes at delivery & $571 / 604(95 \%)$ & $74 / 78(95 \%)$ & $68 / 76(89 \%)$ & $1262 / 1304(98 \%)$ & 0.004 \\
\hline $\begin{array}{l}\text { Active lesions at delivery with ruptured membranes } \\
>4 \text { hours }\end{array}$ & $384 / 599(64 \%)$ & $49 / 78(63 \%)$ & $38 / 77(49 \%)$ & $992 / 1262(79 \%)$ & $<0.001$ \\
\hline Positive viral culture from the occasion before labour ${ }^{\star}$ & $267 / 402(66 \%)$ & $22 / 51(43 \%)$ & $16 / 33(48 \%)$ & $492 / 843(58 \%)$ & $<0.001$ \\
\hline $\begin{array}{l}\text { History of a recurrence without visible lesions on } \\
\text { examination }\end{array}$ & $254 / 599(42 \%)$ & $38 / 75(51 \%)$ & $34 / 76(45 \%)$ & $593 / 1212(49 \%)$ & NS \\
\hline Maternal request for caesarean section & $315 / 597(59 \%)$ & $42 / 75(56 \%)$ & $21 / 77(27 \%)$ & $517 / 1211(43 \%)$ & $<0.001$ \\
\hline
\end{tabular}

^Excluding 1214 where no cultures were taken. 
caesarean section than those in the public sector and female doctors were more likely to examine the genitalia of women in labour than males. Similar discrepancies were noted in a study from the United Kingdom. ${ }^{6}$

Trainees were more familiar with recent developments. For instance, in the case of ruptured membranes of more than 4 hours with a HSV recurrence where there is little evidence that performing a caesarean section would reduce risk to the baby, ${ }^{8}$ trainees were significantly less likely to perform a caesarean section when compared with fellows.

In order to improve the management of genital herpes in pregnancy and reduce the number of unnecessary genital examinations, viral cultures, and sections easily understandable practical guidelines are needed.

On the basis of current evidence what is the appropriate management?

- Women should be informed that the risk of transmission to the newborn is small, even in the face of lesions at delivery. ${ }^{5}$

- In view of the time delay in processing viral cultures, swabs for viral culture are of limited value. ${ }^{10}$

- Suppressive antiviral therapy is of limited value and should not be recommended in late pregnancy. ${ }^{11}$

- Finally, although caesarean section is often recommended to bypass the birth canal, this procedure carries a significant morbidity and a mortality. ${ }^{12}$ However, where a recurrence is noted at the time of delivery, it may still be recommended.
We would like to than Dr P Brockelhurst for allowing us to use a modified version of his questionnaire and Royal Australian College of Obstetricians and Gynaecologists for supplying the details of college fellows, members, trainees, and diplomats.

1 Whitley R, Arvin A, Prober C, et al. A controlled trial comparing vidarabine with acyclovir in neonatal herpes simplex virus infection. Infectious Diseases Collaborative Antivira Study Group. N Engl f Med 1991;324:444-9.

2 Garland SM. Neonatal herpes simplex: Royal Women's Hospital 10-year experience with management guidelines for herpes in pregnancy. Aust NZ $\mathcal{f}$ Obstet Gynaecol 1992;32:331-4

3 Mindel A. Genital herpes the forgotten epidemic. HERPES The fournal of the IHMF 1994;1:39-48.

4 Brown ZA, Selke S, Kopelman J, et al. The acquisition of herpes simplex virus during pregnancy. $N$ Engl f Med 1997:337:509-15.

5 Prober CG, Sullender WM, Yasukawa LL, et al. Low risk of herpes simplex virus infections in neonates exposed to the virus at the time of vaginal delivery to mothers with recurrent genital herpes simplex infections. N Engl f Med 1987; 316:240-4.

6 Brocklehurst P, Carney O, Ross E, et al. The management of recurrent genital herpes infection in pregnancy: a postal survey of obstetric practice. Br F Obstet Gynaecol 1995;102: 791-7.

7 SPSS. Statistical package for the social sciences [computer program], version 7.0. Chicago, IL: SPSS Inc, 1995.

8 American Academy of Pediatrics. Committee on fetus and newborn. Committee on infectious diseases. Perinatal herpes simplex virus infections. Pediatrics 1980;66:147-9.

9 Whitley RJ, Nahmias AJ, Visintine AM, et al. The natural history of herpes simplex virus infection of mother and newborn. Pediatrics 1980;66:489-94.

10 Roberts SW, Cox SM, Dax J, et al. Genital herpes during pregnancy: no lesions, no cesarean. Obstet Gynecol 1995;85: 261-4.

11 Brocklehurst P, Kinghorn G, Carney O, et al. A randomised controlled trial of suppressive acyclovir in late pregnancy in women with recurrent genital herpes infection. $\mathrm{Br} 7 \mathrm{Obstet}$ Gynaecol 1998;105:275-80.

12 Libman MD, Dascal A, Kramer MS, et al. Strategies for the prevention of neonatal infection with herpes simplex virus: a decision analysis. Rev Infect Dis 1991;13:1093-104. 